Journal of Teacher Education for Sustainability, vol. 10, 2008, pp. 42-55

\title{
INTEGRATING KNOWLEDGE, FEELINGS AND ACTION: USING VEE HEURISTICS AND CONCEPT MAPPING IN EDUCATION FOR SUSTAINABLE DEVELOPMENT
}

\author{
Jacqueline Vanhear and Paul J. Pace \\ University of Malta, Malta
}

\begin{abstract}
Although children are regularly showered with environmental knowledge, this is rarely transformed into concerned action, probably because it is not meaningful for the learner and/or is highlighted at the expense of a personalized process of learning. Research in Education for Sustainable Development shows that besides knowledge acquisition feelings, psychological factors and active participation while learning are important determinants of commitment. Fostering an attitude of responsible environmental action is not dependent on what knowledge is delivered, but on how it is delivered and experienced. This paper describes the use of Vee Heuristics and Concept Mapping as pedagogical tools within the context of primary school learners' different learning patterns. It provides illustrations of Concept Maps constructed before and after the learning programme and discusses some implications of the findings. This paper suggests that the use of Vee Heuristics and Concept Mapping along with an awareness of how the child prefers to learn may be steps towards tapping-in the child's internal talking so that educators can understand how each learner responds to incoming information. Learning about environmental issues becomes relevant, meaningful and, in the long run, conducive to improved environmental responsible behaviour.
\end{abstract}

Key words: Vee Heuristics; Concept Mapping; learning process; environmental education; metacognition; meaningful learning.

\section{Education for Sustainable Development: Going beyond transmission of knowledge}

Research and experience have shown that placing greater emphasis on the transmission of environmental knowledge does not significantly impact a learner's concerned action. Content matter needs to be meaningful for the learner and sensitive to the learner's personalised process of learning. Based on this premise, one assumes that what matters is not what knowledge is delivered but how it is delivered and experienced.

Different forms of Environmental Education (EE) were readily taken up by educational institutions - the most recent being Education for Sustainable Development (ESD) - as a means to improve quality of life and counter environmental degradation. 
Although educational programmes succeed in promoting environmental awareness, they have very often failed to produce substantial changes in attitudes, values and committed action. These three original objectives were proposed by the Tbilisi 1977 Conference (UNESCO, 1980) and subsequently reaffirmed at the 1987 Moscow Congress (UNEP, 1987), the 1997 Thessaloniki Conference (Scoullos, 1998) and the 1997 Conference at Ahmedabad (CEE, 2007). The narrow monodisciplinary structures of formal educational institutions traditionally promote the transmission of subject content. In the traditional paradigm, cognition (i.e., the processing of information or knowledge) is highlighted at the expense of feelings and behaviour (Pace, 2000). However, the misconception that the transmission of environmental knowledge would be sufficient to trigger an attitude of responsible action evolved into something more complex where, "the way in which learning occurs is as important as the content" (Orr, 2004: 14).

Borden and Schettino (1979, as cited in Newhouse, 1990) also reveal that the more important determinant of commitment (action) is the level of feeling rather than the level of knowledge. Simmons (1991) defines responsible environmental behaviour not only through cognitive factors, but also through conative and affective factors such as problemsolving skills and psychological factors, including attitudes and the development of selfesteem. Making environmentally responsible decisions requires social and psychomotor skills, as well as affective attributes such as responsibility and commitment toward sustainable development, i.e. the development of a sustainable development ethic. In turn, this is dependant on whether "knowledge is interrelated to personal behaviour and social values, and if the learner experiences ethical demands in decision making" (Schleicher, 1996: 2).

One of the most important factors of commitment is environmental sensitivity, i.e. "a predisposition to take an interest in learning about the environment, feeling concern for it, and acting to conserve it, on the basis of formative experiences" (Chawla, 1998: 9). Furthermore, Chawla explains that formative experiences may be characterized as exchanges between an external environment (physical surroundings, social mediators) and an internal environment (how the child responds to the external environment). Any effective ESD programme, therefore, needs to place the learner and his/her personal development at the centre of the learning programme.

\section{The Let Me Learn Process®: An advanced learning system}

The present study delves deep into the learning process and reveals that if we only look upon cognition, we are only looking at one-third of who the child really is as a learner. This research highlights the Let Me Learn Process (LML), an advanced learning system, whose theoretical basis is the Interactive Learning Model (ILM) (Johnston, 1996, 1998), which proposes that learning is a process occurring because of the continuous interaction of no less than three mental processes: Cognition (I think), Affectation (I feel) and Conation (I act). ILM gives teachers, students, parents, and administrators another means of identifying how each student processes information, uses her/his personal tools for learning, and develops as a confident and successful lifelong-learner. Furthermore, the interaction between cognition, conation, and affectation forms interactive patterns of behaviour within each learner. These patterns consist of sequence, precision, technical reasoning, and confluence (see Table 1). Rather than placing individuals into categories, the Let Me Learn Process emphasizes that each learner uses each of these interactive patterns in concert and to varying degrees. 
Table 1. Summarized description of the four learning patterns

\begin{tabular}{ll}
\hline \multicolumn{1}{c}{ Learning pattern } & \multicolumn{1}{c}{ Learner prefers } \\
\hline Sequence & Order, plans, directions, linear logic, continuity \\
\hline Precision & $\begin{array}{l}\text { Facts, information, documentation, measurement, } \\
\text { correctness }\end{array}$ \\
\hline Technical Reasoning & $\begin{array}{l}\text { Problem solving through design, structure, physical and } \\
\text { pictorial representation without the burden of words, use } \\
\text { of combat engineering to fix physical/abstract problems }\end{array}$ \\
\hline Confluence & $\begin{array}{l}\text { Risk taking, learning through failure, rapid ideation, } \\
\text { extreme imagination, readiness to suspend rules and the } \\
\text { limitations of reality in order to move beyond the known }\end{array}$ \\
\hline
\end{tabular}

To measure the degree to which each learner uses each of the patterns, Johnston and Dainton (2005) developed the Learning Connections Inventory (LCI) that has withstood empirical and theoretical testing for more than ten years in different countries around the world. The LCI scores reveal whether the learner uses a learning pattern at a "Use First" level, "Use as Needed" level or seeks to "Avoid" it altogether.

Information enters the brain through our sensory systems and some of it is processed in our working memory. Some of this information is stored for future retrieval in our long-term memory. Our working memory is similar to “a computer's central processing unit" while our long-term memory is the "computer's hard disk" (Bruer, 1993). Cognitive psychologists claim that long-term memory comes in an array of structures that can either be declarative memory (storing facts and events) or non-declarative memory (storing skills and procedures). Nonetheless, unlike a computer, we do not retrieve information by giving it "an address" in our brain, but by creating associative links between chunks of information. This suggests that new learning is integrated into preexisting structures which psychologists call schemas that effect how we process and interpret incoming information. Bruer argues that "prior knowledge affects how we interpret school instruction and thus affects what we can learn. School instruction that ignores the influence of pre-existing knowledge on learning can be highly ineffective" (Bruer, 1993: 28) and, we add, potentially damaging to a student's plans for further education as success within the system is dependent not on the competency of the learner, but on his/her ability or inability to adapt to the set menu offered by the school.

Similarly, the ILM suggests that when a stimulus enters the brain, the brain sends neural impulses to the mind that translates the impulses into symbols that it can store, process and retrieve while simultaneously checking prior experiences and where they belong within the declarative or non-declarative memory. This is where metacognition comes into play since it is suggested that these symbolic representations are transferred into the non-declarative memory through metacognition. More importantly ILM suggests that our learning patterns form the filter through which the stimulus is communicated to the mind when we are learning (i.e., one responds and interprets incoming information through these learning patterns which occur differently in each learner). Bruer defines metacognition as "the ability to think about thinking, to be consciously aware of oneself as a problem solver, and to monitor and control one's mental processing" (Bruer, 1993: $67)$. It is an intrapersonal communication where time is given to quietly think and 
reflect on what one is learning and on regulating how we go about learning (Vanhear \& Borg, 2000).

Behaviourist learning models emphasise the multistage model of memory where practicing past tasks leads to over learning, resulting in resistance to extinction (Vanhear \& Borg, 2000: 10). This model clearly promotes rote learning. However, ample research (e.g., Freire, 1970; McLaren, 1989; Novak \& Gowin, 1984; Novak, 1998) reveals that the cognitive key to retention is meaningfulness. Metacognition focuses on the active role of the learner and challenges the transmissive view of learning and teaching. Georghiades (2000) reveals that primary school children who received metacognitive instruction performed better. This is because metacognition lends itself to a process of praxis (Vanhear, 2006). The equation is as follows: "by being reflective, revisiting the learning process, making comparisons between prior and current conceptions, and being aware of and analysing difficulties, learners gradually maintain deeper understanding of the learned material ... maintaining better understanding sets the bases for successful transfer" (Georghiades, 2000: 128).

\section{Methodology}

On the basis of the theoretical background presented above, the following research question was constructed: How can teachers help learners to reflect and act upon their knowledge and experience of the environment by helping them construct new meaningful knowledge? This research question revolves around the notion of the learners' structures of knowledge and how they respond to it or as Gardner (1991: 253) argues "we must place ourselves inside the heads of our students and try to understand as far as possible the sources and strengths of their conceptions". This is also what Bruner (1996: 49) sought for throughout his studies "I have long argued that explaining what children do is not enough; the new agenda is to determine what they think they are doing and what their reasons are for doing it".

Consequently, this research made use of two validated tools namely: Vee Heuristics and Concept Mapping, with 6-7 year old pupils in a mixed ability girls' primary school, to improve on meaningful learning of specific environmental knowledge related to biodiversity. Although a whole class participated in the learning programme of this research, only nine girls (with different learning patterns through the use of the LCI) were randomly selected for the in-depth study.

Since Gowin's original Vee Heuristic was too complex for 6 year olds, the study opted for Ahoranta's adapted version of Åhlberg's improved Vee (Åhlberg \& Ahoranta, 2002 ) to trace the learning process. The steps in the Vee Heuristic were used as questions in semi-structured interviews carried out with the sample to chart each learner's individual learning experience. The interviews provided details about the learners' knowledge and misconceptions about the chosen topic and how these developed to construct new meaningful knowledge. Concept Maps were constructed by the children before and after the learning process and the differences that emerged and their implications were discussed with the children. The different learning patterns of the pupils and their contribution to diverse structures of knowledge were taken into consideration, discussed and evaluated. 


\section{Data Analysis}

This section of the paper will present, analyse and discuss in detail the learning patterns of two learners with two different learning profiles.

Maria (her LCI scores are summarised in the grid below)

\begin{tabular}{lcl}
\hline Learning pattern & LCI Score & Preference \\
\hline Sequence & 16 & Avoid \\
\hline Precision & 22 & Use as Needed \\
\hline Technical Reasoning & 27 & Use First \\
\hline Confluence & 20 & Use as Needed \\
\hline
\end{tabular}

Maria is a dynamic learner (Johnston, 2005) who makes use of Technical Reasoning at a Use First level. She uses her Confluent and Precise processing as needed while she avoids Sequence processing. From this learning pattern, one can deduce that Maria does not like to write in detail, makes use of very few words to express herself, prefers to work by herself and needs to see the purpose for what she is doing. Furthermore, she tends not to read directions since she finds following directions quite confusing if not even frustrating.

On examining Maria's Vee Heuristic (Figure 1) one notes the difference in the answers on each side. On the left hand side, which reveals responses given before the learning programme took place, one can note this girl's uncertainty in going through the programme. Reply No.1 is quite vague whereas reply No. 4 shows that she is not sure from where she can get an answer. This observation is substantiated by her first drawing constructed prior the learning programme (Figure 3). This clearly conveys the message how lost this child felt before going through this learning programme.

Maria's reply to Question 5 substantiates her preferred way of learning. In fact, although the teacher carried out many lessons and activities such as poems and provided detailed information about insects, this girl mentioned only the outing, the computer, books and pictures as her primary sources for learning. This exemplifies how learners who score high in technical reasoning and "use as needed" the confluent and precise patterns prefer to learn.

On the other hand, the right hand side reveals a difference in this girl's confidence. Her response to Question 5 was quite immediate, detailed and sure, thus showing that her sense of security and motivation increased along the learning programme. Furthermore, it is quite appealing to note the response to Question 8: "because now I know more and because I can show that I studied". One of this learner's main concerns is not what she learnt, but how she is going to show it. In fact, this learner's learning patterns reveal that she finds it difficult to express what she knows, especially through tests, since she does not like writing in detail or following too many sequential directions. It is no wonder that she is concerned about this, she is aware that she has the necessary knowledge but she has difficulty expressing it. From reply No. 8 one can conclude she was satisfied she was able to externalize what she had learned. Concept Mapping offered her another way of expressing what she knows. When asked what she thought about her second Concept Map (Figure 4), when she compared it to her first (Figure 2), she replied: "it shows that I have studied", something learners who primarily uses technical reasoning are often accused of not doing because they do not consider it important to 
tell others what they know! Referring this learner's learning patterns, it is clear that she avoids instructions and finds difficulty in expressing what she learns in words, instead she prefers to learn through hands-on experience and the responses given in the Vee Heuristic and drawings convey that this girl's motivation increased throughout this process since the learning experience was congruent with her preferred way of learning.

2. Why do you think it's important to know more about this question?

Because I love animals

3. What do you know about this question? Construct a first Concept Map.

Figure 2: first Concept Map

Figure 3: first drawing

4. From where can you get an answer to your question?

I don't know ... maybe from books or in the gardens
1. Make your question What is an insect?
8. Why is the new information important for you? Because now I know more and I can show that I studied
7. What new information did you know? Construct a second Concept Map.

Figure 4: second Concept Map

Figure 5: second drawing

6. What kind of information did you collect?

About insects

5. What did you do in order to find an answer to your question?

We looked at the computer, books and pictures

We went to a place where I could look at insects

Figure 1. Maria's Vee Heuristic

Even a cursory comparison of the two Concept Maps, presented in Figures 2 and 4 shows that the number of concepts and propositions increased, indicating that significant learning had taken place. The interview with this girl revealed how quickly she was changing and adding to her map. This evidences her confidence and eagerness to show what she learnt and shows how easy it was for her to externalize her cognitive structures in this way. She enjoyed watching her map expand. Consequently, she was able to correct all the misconceptions present in the first Concept Map such as that "insects have 2 or 4 legs", "insects are not useful" or "insects eat honey". 


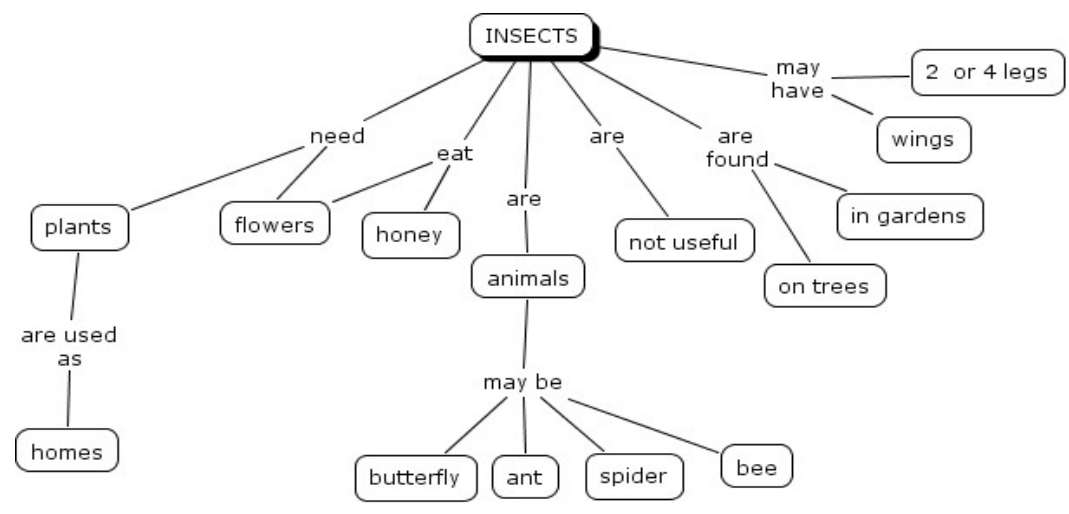

Figure 2. Maria's first Concept Map before the learning program

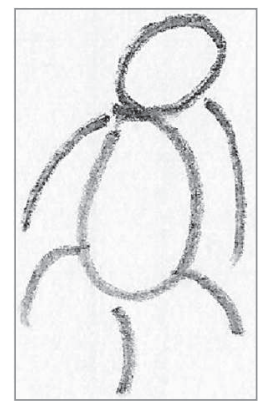

Figure 3. Maria's first drawing before the learning program

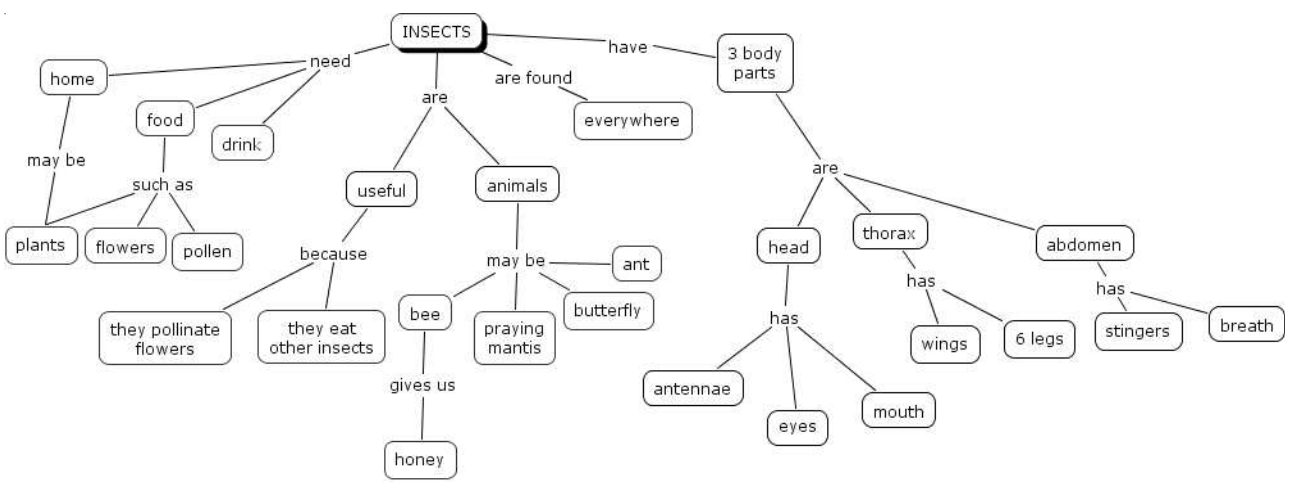

Figure 4. Maria's second Concept Map after the learning program

This learner's motivation through this kind of process of learning is also very explicit in her drawings. Figure 5 reveals the radical change that took place within this learner's motivation to learn. In fact, the second drawing gives more precise details than her initial drawing (Figure 3).

The changes present in the Vee, in the Concept Maps and the drawings clearly demonstrate that learning in this way increased the learners' motivation thus affecting 
positively on their learning. Moreover, Concept Maps seemed to offer a practical and organised way to exhibit what they learned.

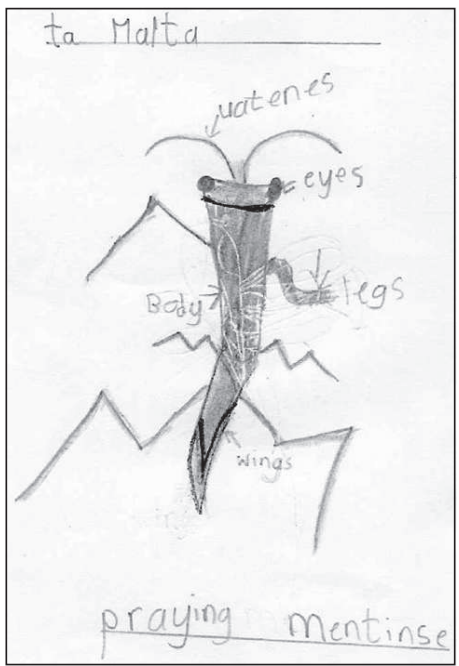

Figure 5. Maria's second drawing after the learning program

Rita (her LCI scores are summarised in the grid below)

\begin{tabular}{lcl}
\hline Learning pattern & LCI Score & Preference \\
\hline Sequence & 28 & Use First \\
\hline Precision & 26 & Use First \\
\hline Technical Reasoning & 21 & Use as Needed \\
\hline Confluence & 16 & Avoid \\
\hline
\end{tabular}

Rita's LCI score reveals that she "uses at first" level her Sequence and Precise patterns, the Technical Reasoning pattern is "used as needed" while she "avoids" the Confluent pattern. This means that this learner needs clear step-by-step directions, wants to do her work neatly and wants to know whether she's meeting her teachers' expectations. She also tends to want thorough explanations and asks a lot of questions. She likes details and she prefers written work to show what she has learnt. When needed she can also learn through hands-on experience, while, on the other hand, this learner avoids taking risks and prefers her work to be as accurate and as correct as possible.

Rita's Vee Heuristic (Figure 6) discloses a lot of useful information about how she prefers to learn. The left hand side reveals why is it important for her to want to know more. Furthermore, her reply to Question 4 conveys how she plans to learn and with the knowledge of how her learning patterns work most efficiently for her, both the teacher and the student can together build a learning programme which would make sense to the learner. Rita plans to learn through books and the teacher (Sequence and Precision) but also through outings (Technical Reasoning). Her learning patterns are evidenced also in her reply to Question 5, which shows what the learner actually did in order to learn. This substantiates her learning patterns since she mentioned books, the computer, the outing and also a poem. 
Therefore, her primary sources for learning occurred in the classroom setting but having a score of 21 in Technical Reasoning where she makes "use as needed" of this learning pattern, she also mentioned the outing as another source for her learning. The right hand side of the Vee Heuristic exhibits how the learner constructed and developed her knowledge. Her reply to Question 6 shows that she developed her knowledge about the importance of leaves as exhibited in her second Concept Map presented in Figure 6. In Question 8 she was able to compare her prior knowledge with the present knowledge and in fact, learners with this kind of learning pattern are very good in comparing.

2. Why do you think it's important to know more about this question? Because it's fun and I enjoy learning things

3. What do you know about this question? Construct a first Concept Map. Figure 7: first Concept Map

4. From where can you get an answer to your question? From our teacher, from books and magazines and from many other things like outings
1. Make your question Why do leaves fall off a tree?
8. Why is the new information important for you? Because I got to know more things about leaves that Ididn't know
7. What new information did you know? Construct a second Concept Map.

Figure 8: second Concept Map

6. What kind of information did you collect?

That leaves are very important for us, they give us oxygen and they are important for trees because they move food and water

5. What did you do in order to find an answer to your question?

I didn't know everything about leaves, but then I learned from books, the computer, we went for an outing. We did a poem called Seasons of Trees

Figure 6. Rita's Vee Heuristic

By comparing the Concept Maps in Figures 7 and 8 which were respectively constructed before and after the learning programme one can easily note an increase in concepts and propositions. There is also evidence where prior knowledge was developed, misconceptions corrected and new knowledge constructed. This learner went into greater detail in her second Concept Map like, for example, on the concept "different shapes" she added "compound", "simple", "narrow" and "wide", or to the linking phrase "fall off" she added four other different appropriate concepts. She was also able to correct her misconception that "leaves fall off in spring". One of the most remarkable details was that she was able to exhibit the proposition "in autumn comes out [they show] their real colour such as red, orange, yellow". 


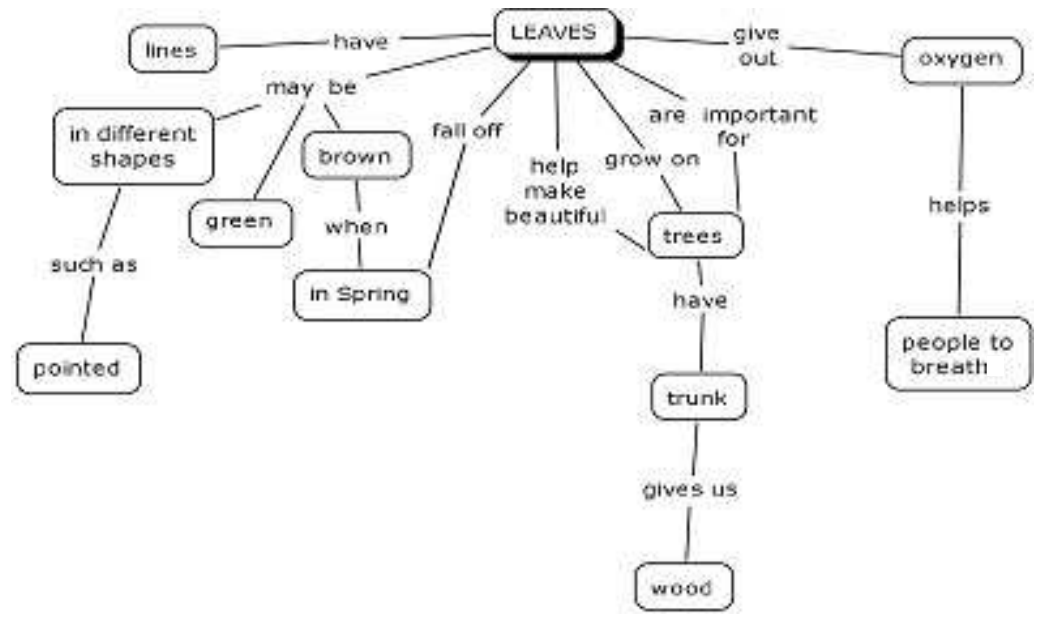

Figure 7. Rita's first Concept Map before the learning program

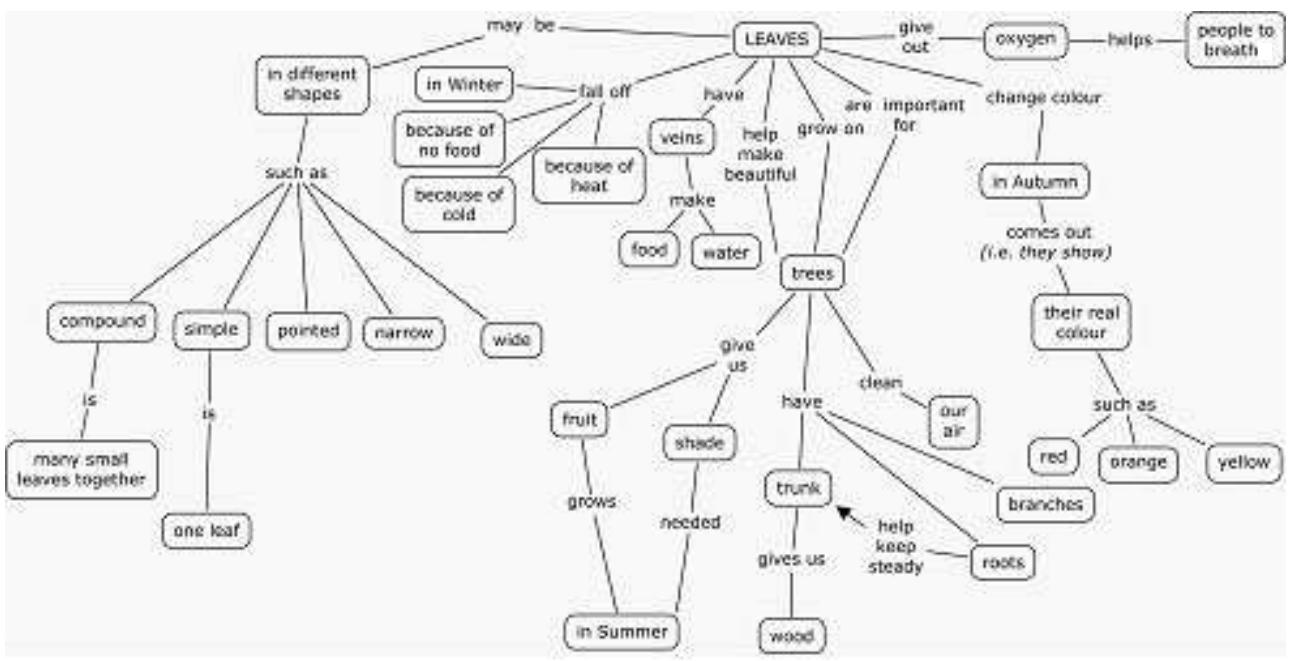

Figure 8. Rita's second Concept Map after the learning program

\section{Discussion}

The research data reveal that all of the learners were able to construct new meaningful knowledge when presented with a learning programme which suited their preferred way of learning and when they were actively involved in their own learning. Furthermore, since the Vee Heuristic process captures all of the three mental processes involved in learning, namely cognition (I think), conation (I act) and affectation (I feel), the learners' will to learn was increased and consequently their performance was enhanced. This research challenges conventional and restrictive classroom practices that emphasize rote learning at the price of meaningful learning because learners are considered passive recipients rather than dynamic actors who commit themselves to thinking, acting and 
learning critically. The data collected in this research reveals that each learner processes incoming information differently and it is very unrealistic to expect all children to respond to whatever happens in class in approximately the same way. Furthermore, it reveals that different learners learn in different settings and therefore not all learners learn best in a non-traditional setting and vice-versa (Zelezny, 1999). The results confirm that, for a learner "to take interest in learning", the teacher must be aware of the learner's own preferred way of learning in order to address his/her needs and enhance his/her learning experience. This is where the LML can be valuable since it reveals how each learner prefers to learn and how he/she responds to incoming information.

The Vee Heuristic lent itself beautifully to a process of reflection and action, where the child's internal talking became visually overt and explicit. In this way learners are taught to think aloud and reflect on what is going on in their heads and how they can proceed to act and develop it. Research has shown that new meaningful knowledge does not occur in a vacuum (Bruer, 1993; Johnston, 1996, 1998; Novak, 1998) and, therefore, prior knowledge has to be taken into consideration if we expect meaningful learning to take place. By constructing Concept Maps for the focus question under study, the children clearly conveyed at a glance, "what they already know" thus providing educators with the opportunity to build upon it. The two Concept Maps constructed before (on the left hand side of the Vee) and after (on the right hand side of the Vee) the learning programme were very effective in allowing both the teacher and the learner to easily see what prior knowledge was present, what new knowledge was constructed and how this was integrated within the pre-existing cognitive structure and elaborated. One has also to bear in mind that for learners who are used to learning through rote or memorisation of facts, Concept Maps may offer quite a challenging task at first and it may take some time before they feel comfortable working with them.

The integration of these metacognitive tools: the Vee Heuristic, Concept Mapping along with an understanding of how the learner prefers to learn, provides the teacher (and the learner) with a clear picture of how the learner responds to and acts upon incoming information. These metacognitive teaching strategies shift the control from the teacher to the learner (Bruer, 1993). Consequently, learners become the agents of their own learning since they are actively participating in their own learning process. Moreover, the learner exhibits how he/she plans to learn more and this is very important for the teacher to be able to collaboratively build a learning programme which would be relevant to the learner's way of responding to new information and so prove to be truly motivating and meaningful.

\section{Conclusion}

ESD promotes a particular lifestyle which highlights not only knowledge but also feelings and attitudes that call for commitment and responsibility towards sustainable development. It is dependent on informed action and the development of autonomous critical learners. The methodology proposed by the study proved to be an effective way of giving the learner ownership of learning in a way that she/he is conscious of how she/ he is learning and can, in this way, direct (i.e., is empowered) its course. A paradigm shift has to occur in the way we see things, prevailing discourses about learning have to be questioned and this is why various authors (O'Sullivan, 1999; Orr, 2004; King, 
2005) are now calling for a transformative vision of learning - not just the transformation of students into functional citizens, but also the transformation of the learning institutions themselves to provide these enabling pedagogies. Effective ESD at formal education institutions is dependent on a change in praxis; and change is not always a welcomed alternative. Consequently, alternative methodologies are viewed with suspicion and need to be acknowledged and legitimized within the institutions' administrative structures for them to proceed.

Concept Maps and Vee Heuristics lend themselves to this process of transformation for both the teacher and the student. It is a process through which the prevailing model of education is challenged. This research has shown that the use of these two tools facilitates the achievement of ESD targets and may, in the long run, bring about desired environmental responsible behaviour. This is because these two tools present a process of praxis and through their use learners are trained in decision-making, reflective and problem solving skills by effectively identifying the child's "internal environment" and leading them to understand what is going on in their heads and why and how they respond differently to different situations. Equipped with such awareness teachers and students may form partnerships based upon the knowledge of each other's ways of processing incoming information and be able to create an atmosphere in which they have the opportunity to formulate specific techniques and strategies for developing meaningful learning. However, the characteristics of and how this translates from meaningful knowledge to responsible environmental action need to be studied further.

\section{References:}

Åhlberg, M. \& Ahoranta, V. (2002) Two improved educational theory based tools to monitor and promote quality of geographical education and learning. International Research in Geographical and Environmental Education, 11(2), 119-137.

Bruer, J. T. (1993) Schools for Thought: A Science of Learning in the Classroom. Massachusetts: The MIT Press Cambridge.

Bruner, J. (1996) The Culture of Education. USA: Harvard University Press.

CEE (Centre for Environmental Education) (2007) Moving forward from Abmedabad Environmental Education in the 21st Century. 4th International Conference on Environmental Education. Ahmedabad, India, 26-28 November 2007. Retrieved March 2008 from http://www.tbilisiplus30.org/Final Recommendations.pdf

Chawla, L. (1998) Significant life experiences revisited: A review of research on sources of environmental sensitivity. The Journal of Environmental Education, 29(3), 1121.

Freire, P. (1970) Pedagogy of the Oppressed. UK \& USA: Penguin Books.

Gardner, H. (1991) The Unschooled Mind. New York: Basic Books.

Georghiades, P. (2000) Beyond conceptual change learning in science education focusing on transfer, durability and metacognition. Educational Research, 42 (2), 119-139.

Johnston, C. A. (1996) Unlocking the Will to Learn. California: Corwin Press.

Johnston, C. A. (1998) Let Me Learn. California: Corwin Press.

Johnston, C. A. (2005) Learning to Use My Potential: A Catalogue of Resources. Turnersville, NJ: Learning Connections Resources. 
Johnston, C. A. \& Dainton, G. (2005) Learning Connections Inventory. Turnersville, NJ: Learning Connections Resources.

King, K. P. (2005) Bringing Transformative Learning to Life. Malabar, FL: Krieger.

Mclaren, P. (1989) Life in Schools. White Plains, New York: Longman.

Newhouse, N. (1990) Implications of attitude and behaviour research for environmental conservation. Journal of Environmental Education, (22)1, 26-32.

Novak, J. D. (1998) Learning, Creating, and Using Knowledge: Concept Maps as Facilitative Tools in Schools and Corporations. Mahweh, NJ: Lawrence Erlbaum Associates.

Novak, J. D. \& Gowin, D. B. (1984). Learning How To Learn. USA: Cambridge University Press.

Orr, D. W. (2004) Earth in Mind: On Education, Environment, and the Human Prospect. Washington: Island Press.

O'Sullivan, E. (1999) Transformative Learning: Educational Vision for the 21st Century. London \& New York: Zed Books.

Pace, P. (2000) Attitudes towards environmental education in the Maltese formal education system, in Leal Filho W. (ed.) Communicating Sustainability. Environmental Education, Communication and Sustainability Series No. 8. Frankfurt am Main, Peter Lang.

Schleicher, K. (1996) Environmental ethics, in Leal Filho, W., MacDermot, F. \& Padgham, J. (eds.) Implementing Sustainable Development at University Level. UK: European Research \& Training Centre on Environmental Education, University of Bradford.

Scoullos, M. J. (1998) (ed.) Environment and Society: Education and Public Awareness for Sustainability. Proceedings of the Thessaloniki International Conference, 8-12 December 1997. UNESCO \& Government of Greece.

Simmons, D. A. (1991) Are we meeting the goal of responsible environmental behaviour? An examination of nature and environmental education center goals. Journal of Environmental Education, 22(3), 16-21.

UNEP (1987) Connect, Vol. XII, No. 3. September 1987.

UNESCO (1980) Environmental Education in the Light of the Tbilisi Conference. France: UNESCO.

Vanhear, J. (2006) Vee Heuristics, Concept Mapping and Learning Patterns in Environmental Education: Merging Metacognitive Tools and Learning Processes to improve facilitation of learning with primary school children. Unpublished M. Ed. Thesis: University of Malta.

Vanhear, J. \& Borg, A. (2000) The Interactive Learning Model: Profiling Learners' Learning Patterns. Unpublished B.Ed. Thesis: University of Malta.

Zelezny, L. (1999) Educational interventions that improve environmental behaviours: A meta-analysis. The Journal of Environmental Education, 31(1), 5-14.

This paper is just a very small part of a larger research project presented as a Masters in Education Theses for the University of Malta (Vanhear, 2006). 


\section{Correspondence:}

Jacqueline Vanhear, St.Joseph, Mater Boni Consilii School, Paola PLA1613, Malta. Email: jacvan@gmail.com

Received 27 April 2008; revised version received 15 November, 2008 